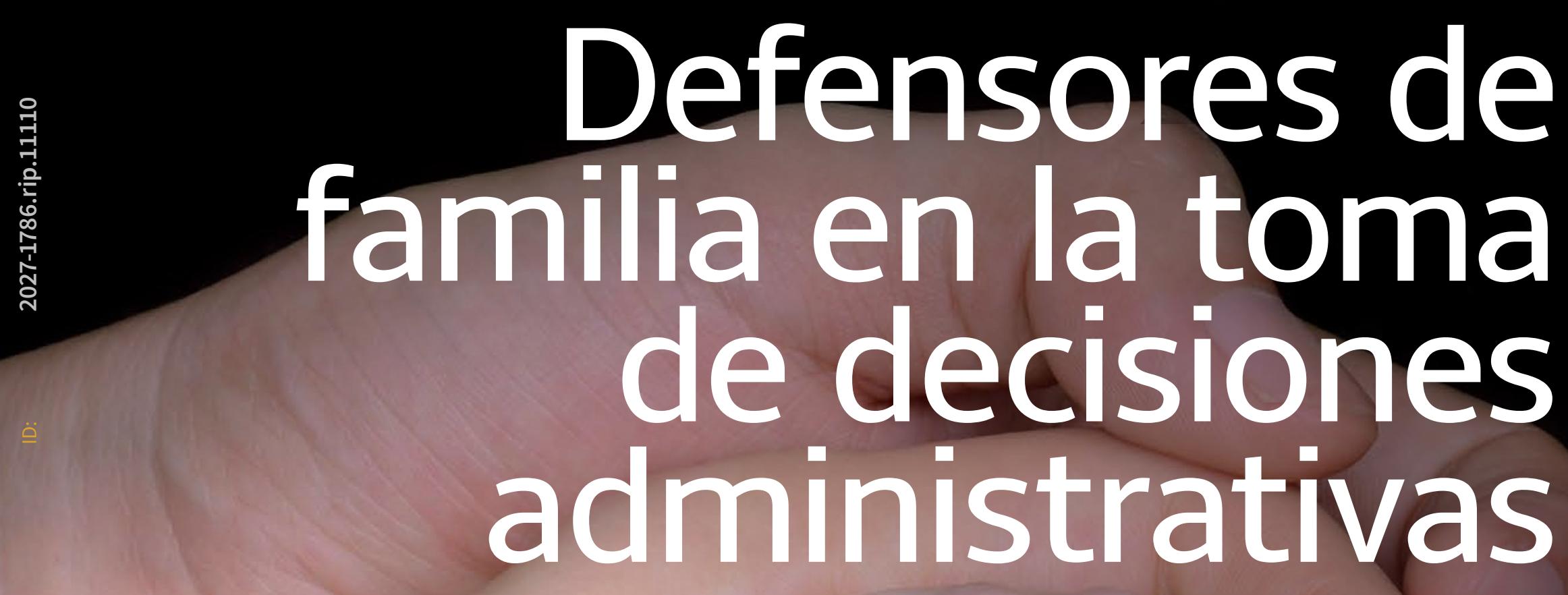

Actitudes implícitas y explícitas

Family advocates in the administrative take of decisions: implicit and explicit attitudes

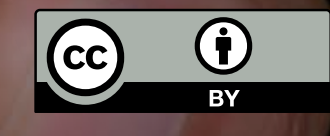

Luz Mery Liscano Cleves

Mercy Y. Polania Garzón

Luis Alberto Quiroga Baquero
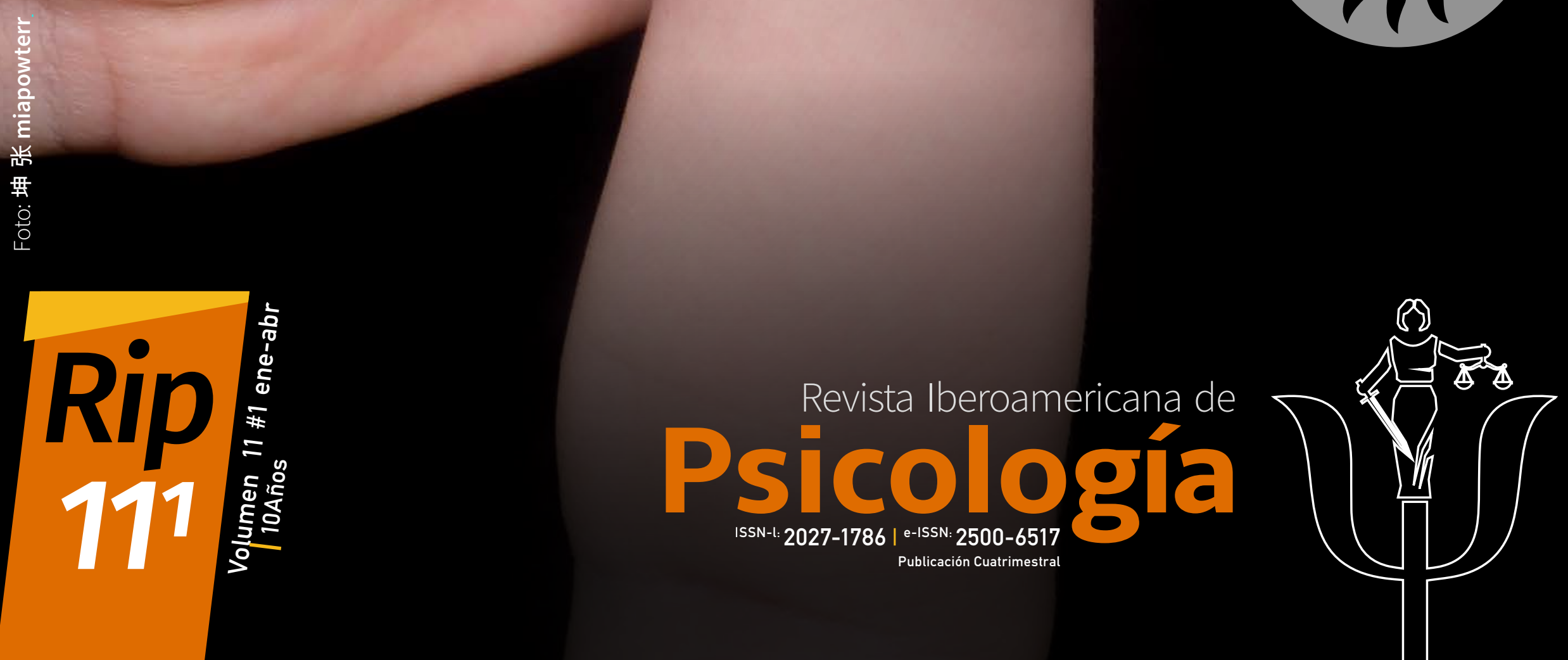
Revista Iberoamericana de

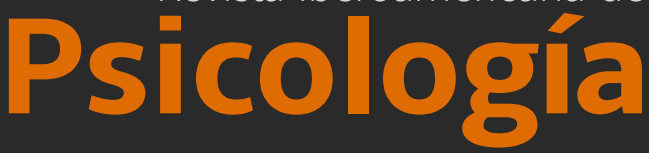

ISSN-I: 2027-1786 | e-ISSN: 2500-6517 Publicación Cuatrimestral

ID:

\section{7-1786.rip.11110}

Title: $\quad$ Family advocates in the administrative take of decisions

Subtitle: Implicit and explicit attitudes

Título: Defensores de familia en la toma de decisiones administrativas

Subtítulo: Actitudes implícitas y explícitas

Alt Title / Título alternativo:

[en]: Implicit and explicit attitudes of family advocates in administrative decision making

[es]: $\quad$ Actitudes implícitas y explícitas de defensores de familia en la toma de decisiones administrativas

Author (s) / Autor (es):

Liscano Cleves, Polania Garzón, \& Quiroga Baquero

Keywords / Palabras Clave:

[en]: $\quad$ implicit and explicit attitudes; bias; decision-making; implicit association test; family advocates

[es]: $\quad$ actitudes implícitas y explícitas; sesgo; toma de decisiones; test de asociación implícita; defensores de familia

Submited: 2017-05-19

Acepted: 2017-07-25

\section{Resumen}

En la presente investigación se evaluaron

las actitudes implícitas y explícitas de una muestra de defensores de familia adscritos a los Centros Zonales del Instituto Colombiano de Bienestar Familiar (Huila-Colombia), frente a atributos relacionados con las dimensiones de vulnerabilidad o generatividad y conceptos relacionados con factores socio-demográficos de los cuidadores. Lo anterior se llevó a cabo mediante un cuestionario de actitudes explícitas y cinco Test de Asociación Implícita

(oficios, sexo, estatus socio-económico, orientación sexual y edad). Los resultados revelaron sesgos implícitos y explícitos con efectos moderados al asociar los atributos

de generatividad y vulnerabilidad con los

conceptos relacionados con oficios, estatus

socioeconómico y orientación sexual, evidenciando preferencias por oficios de tipo profesional, orientación sexual heterosexual y estatus socio-económico alto. Estos hallazgos

se discuten en torno a la relación entre

cognición implícita y la toma de decisiones judiciales y administrativas, así como en torno a la necesidad de formación de los operadores legales acerca de esta relación.

\section{Abstract}

The present research evaluated the implicit and explicit attitudes of a sample of family advocates (assigned to the Zonal Centers of the Institute of Family Wellbeing (Instituto Colombiano de Bienestar Familiar (ICBF)

in Huila, Colombia)|concerning attributes related to the dimensions of vulnerability or generativity and concepts related to sociodemographic factors of caregivers. This was carried out using an explicit attitudes questionnaire and five Implicit Association Tests (occupation, gender, socio-economic status, sexual orientation, and age). The results showed implicit and explicit biases with moderate effects by associating the attributes of generativity and vulnerability with concepts related to occupations, socioeconomic status, and sexual orientation, evidencing preferences

for professional occupations, heterosexual orientation, and high socio-economic status.

These findings are discussed around the relationship between implicit cognition and judicial and administrative decision making, as well as the need for training in legal operators about this relationship.
Citar como:

Liscano Cleves, L. M., Polania Garzón, M. Y., \& Quiroga Baquero, L. A. (2018). Defensores de familia en la toma de decisiones administrativas: Actitudes implícitas y explícitas. Revista Iberoamericana de Psicología issn-l:2027-1786, 11 (1), 101-111.

Obtenido de: https://revistas.iberoamericana.edu.co/index.php/ripsicologia/article/view/1211
Lic Luz Mery Liscano Cleves, MABSwsp

Source I Filiacion:

Universidad Santo Tomás de Colombia

BIO:

Licenciada en Educación Preescolar de la Universidad Pedagógica Nacional; Trabajadora Social de la Fundación Universitaria

Monserrate; Especialista en Intervención Sistémica y Familia de la Universidad Santo Tomás; Maestría en Psicología Jurídica de la Universidad Santo Tomás; Servidora Pública del Instituto Colombiano de Bienestar Familiar

City I Ciudad:

Bogotá DC [co]

e-mail:

luzliscano@usantotomas.edu.co
Mercy Y. Polania Garzón, MA Psi

Source I Filiacion:

Universidad Santo Tomás de Colombia

BIO:

Psicóloga de la Universidad Nacional Abierta y a Distancia; Maestría en Psicología Jurídica de la Universidad Santo Tomás; Servidora Pública del Instituto Colombiano de Bienestar Familiar.

City I Ciudad:

Bogotá DC [co]

e-mail:

mercypolania@usantotomas.edu.co
Luis Alberto Quiroga Baquero, MSc Psi

AutorID: $\quad 57188924222$

ORCID: $\quad$ 0000-0002-9646-9860

Source I Filiacion:

Universidad Santo Tomás de Colombia

BIO:

Psicólogo de la Universidad Nacional de Colombia; Maestría en Psicología Universidad Nacional de Colombia

City I Ciudad:

Bogotá DC [co]

e-mail:

luisquiroga@usantotomas.edu.co 


\title{
Defensores de familia en la toma de decisiones administrativas Actitudes implícitas y explícitas
}

Family advocates in the administrative take of decisions: implicit and explicit attitudes

\author{
Luz Mery Liscano Cleves \\ Mercy Y. Polania Garzón \\ Luis Alberto Quiroga Baquero
}

\section{Introducción}

Las personas continuamente toman decisiones a lo largo de sus vidas, hacen elecciones que implican tomar un curso de acción que conlleva ciertas consecuencias las cuales pueden afectarlos tanto a sí mismos como a otros, ya sea de manera positiva o negativa y a corto o largo plazo. En algunos casos estas decisiones son tomadas con base en una cuidadosa estrategia algorítmica y lógica que contempla la información disponibles de los hechos, la probabilidad de ocurrencia de ciertos eventos y las relaciones de dependencia entre estos; en otros casos se toman decisiones de forma automática, intuitiva y frecuentemente motivadas por estados emocionales, sesgos, prejuicios, etc. (Lerner, Li, Valdesolo, \& Kassam, 2015; Kahneman D. , 2012).

Si bien todas las personas se enfrentan a situaciones de elección y toma de decisiones en su cotidianidad, hay algunos casos en los que, por disposición de un sistema normativo específico, se delega a alguien la toma de decisiones sobre estados de cosas de terceros. Este es el caso de las autoridades legales, quienes por encargo de tipo judicial (eg: jueces) o administrativo (eg: defensores de familia) deben emitir conceptos sobre algún tipo de conflicto, a menudo contando con información parcial y dependiendo de la jurisdicción correspondiente.

En particular en el Estado colombiano los defensores de familia estánencargados, entreotrascosas, detomardecisionesadministrativas acordes con el Código de Infancia y Adolescencia (Ley 1098 de 2006), con el fin de prevenir, garantizar y restablecer los derechos de los niños, niñas y adolescentes (NNA). La actuación administrativa toma lugar cuando el defensor, el comisario de familia o el inspector de policía tienen conocimiento sobre una posible inobservancia, vulneración o amenaza a los derechos de NNA consagrados en esta misma ley. En consecuencia, se da inicio a la respectiva investigación, recabando las pruebas necesarias para determinar los hechos que constituyen la presunta vulneración o amenaza. Para tal fin, el defensor de familia cuenta con un equipo técnico interdisciplinario compuesto, al menos, por un psicólogo, un trabajador social y un nutricionista, quienes se encargan de evaluar e identificar los factores de vulnerabilidad y de generatividad presentes en la situación familiar en la que se encuentra el $\boldsymbol{N} \boldsymbol{N A}$, lo anterior con el fin de emitir un concepto con carácter de dictamen pericial (Ley 1098 de 2006).

El Instituto Colombiano de Bienestar Familiar (ICBF, 2017) plantea que las condiciones de vulnerabilidad refieren a los aspectos que constituyen un riesgo para los miembros de una familia (incluyendo al $\boldsymbol{N N A}$ ), mientras que las condiciones de generatividad corresponden a aquellos aspectos protectores para el desarrollo de la familia. En este sentido, se concibe a la familia como un sistema vivo que puede ubicarse dentro de un continuo vulnerabilidad-generatividad que comprende "la acumulación de riesgos a los que está sometida en un momento dado, con su capacidad para afrontar y aprovechar las vicisitudes para avanzar en su curso vital” (ICBF, 2008, pág. 64).

La labor de los miembros del equipo interdisciplinario consiste en evaluar siete aspectos constitutivos del sistema familiar (ver Tabla 1) mediante una guía de entrevista semi-estructurada para el análisis funcional y sociodemográfico, y una escala con cuatro valores: crítico o en riesgo (situación de vulnerabilidad), aceptable u óptimo (situación de generatividad). En este sentido, la (OIM/WMO, 2013) enfatiza que:

"no son los eventos en sí mismos los que hacen a una familia
más o menos vulnerable, sino la forma como conjuga en cada
momento, el sentido que les asignan a sus circunstancias, la
acumulación de eventos perturbadores y la capacidad para
activar los recursos internos y externos de afrontamiento.
(OIM/WMO, 2013, pág. 64)

Respecto a los actos administrativos adelantados por los operadores legales en el ICBF, en el primer semestre del año 2015 se declaró un total de: $\mathbf{7 7 , 2 1 0}$ NNA en estado de vulneración; $\mathbf{9 , 5 0 2}$ en adoptabilidad; más de $\mathbf{5 , 0 0 0}$ a quienes no se les había restablecido su derecho de crecer en una familia; y una cantidad similar que ya había cumplido la mayoría de edad bajo la protección del Estado. Sin embargo, para ese mismo periodo se reporta tan solo $\mathbf{1 , 1 8 2}$ operadores legales administrativos para resolver los citados casos (Colprensa, 2015). 


\section{Defensores de familia en la toma de decisiones administrativas}

Actitudes implícitas y explícitas

Jiménez Barros (2012) llama la atención sobre las múltiples funciones asignadas al defensor de familia, entre las que se encuentran:

$\rightarrow$ ser administrador de justicia dentro del proceso administrativo de restablecimiento de derechos, tanto en asuntos conciliables como no conciliables.

$\rightarrow$ ejecutar funciones de carácter judicial como abogado representante de los intereses de los $N$ NA dentro de la jurisdicción de familia y el Sistema Penal de Responsabilidad para Adolescentes.

$\rightarrow$ ejecutar funciones policiales como las de allanamiento y rescate, expresas en el Artículo 106 del Código de Infancia y Adolescencia.

Teniendo en cuenta lo anterior, Jiménez Barros (2012) reitera que esta situación, sumada a la escasa disponibilidad de recursos logísticos, humanos y de infraestructura, impacta la eficiencia y eficacia en el cumplimiento de estas múltiples funciones, lo que conlleva posibles afectaciones al el sistema jurídico-legal colombiano y a los proyectos de vida de los NNA y sus familias.

Tabla 1 Categorías de evaluación del sistema familiar por parte del equipo interdisciplinario de la defensoría de familia

\begin{tabular}{|c|c|}
\hline Categoría & Descripción \\
\hline $\begin{array}{l}\text { 1. Relaciones } \\
\text { familiares }\end{array}$ & $\begin{array}{l}\text { Refiere a los patrones de interacción entre los miembros de la familia } \\
\text { en los subsistemas conyugal, parental, fraterno y de la familia, con } \\
\text { otros sistemas (familia extensa, relaciones laborales, entre otros). }\end{array}$ \\
\hline $\begin{array}{l}\text { 2. Curso de } \\
\text { vida familiar }\end{array}$ & $\begin{array}{c}\text { Refiere a la secuencia de estadios que atraviesan las familias como } \\
\text { proceso evolutivo a lo largo de su historia. El paso de un estadio a } \\
\text { otro genera crisis de desarrollo, las cuales son esperables de acuerdo } \\
\text { con las características de los contextos culturales y las experiencias } \\
\text { particulares. En esta categoría se debe identificar las capacidades de } \\
\text { ajuste y nueva acomodación del sistema familiar. }\end{array}$ \\
\hline $\begin{array}{l}\text { 3. Prácticas de } \\
\text { crianza }\end{array}$ & $\begin{array}{c}\text { Refiere a las pautas, prácticas y creencias para cumplir con } \\
\text { las funciones parentales de orientación, protección y control, } \\
\text { necesarias el desarrollo de los NNA acorde con su edad y condiciones } \\
\text { particulares. }\end{array}$ \\
\hline $\begin{array}{l}\text { 4. Experiencias } \\
\text { significativas }\end{array}$ & $\begin{array}{c}\text { Refiere a la manera particular como la familia vive situaciones } \\
\text { que ocurren de manera inesperada y que generan desajustes o } \\
\text { crisis que no son propios del curso de vida familiar. Gracias a estas } \\
\text { experiencias se pueden identificar las capacidades con que la familia } \\
\text { afronta, es decir, su capacidad de respuesta para lograr un nuevo } \\
\text { ajuste. }\end{array}$ \\
\hline $\begin{array}{l}\text { 5. Manejo de } \\
\text { conflictos }\end{array}$ & $\begin{array}{l}\text { Refiere a la manera particular de afrontamiento de las situaciones } \\
\text { de conflicto, específicamente a la posibilidad de asumirlo como una } \\
\text { oportunidad de desarrollo. }\end{array}$ \\
\hline $\begin{array}{l}\text { 6. Manejo de } \\
\text { emociones }\end{array}$ & $\begin{array}{l}\text { Refiere a la forma particular como los miembros de la familia } \\
\text { expresan y reciben las emociones en su vida cotidiana. }\end{array}$ \\
\hline
\end{tabular}

7. Actitudes con los NNA (hijos, familiares u otros) que habitan en el hogar.

Tomado del documento: Lineamiento técnico de modalidades para la atención de NNA, con derechos inobservados, amenazados o vulnerados (Instituto Colombiano de Bienestar Familiar, 2017).

En este panorama destaca un aspecto fundamental del quehacer de los defensores de familia: la dimensión psicológica de la toma de decisiones jurídicas y los factores vinculados a esta. Siguiendo esta línea, el foco de interés de la presente investigación se centra en la forma en que los procesos cognoscitivos y conductuales, vinculados a la toma de decisiones, se ven afectados por los factores constitutivos del ambiente social (eg: sistemas normativos) y físico en la historia ontogenética de los individuos.

Desde la psicología y en concurso interdisciplinario con otras ciencias, en el campo de estudio de los fenómenos relacionados con la toma de decisiones se ha reconocido la existencia de dos grandes perspectivas: los modelos normativos y los modelos descriptivos (Over, 2004). Los primeros enfatizan que la toma de decisiones es el resultado de la aplicación de algoritmos cuya trayectoria permite a los individuos optimizar y maximizar las utilidades (consecuencias beneficiosas). Así, la toma de decisiones puede ser entendida como conducta racional, en tanto es susceptible de ser explicada de forma prescriptiva en términos de la lógica formal, como la deducción de reglas de preferencia a partir de axiomas que aseguren el mejor resultado posible a partir del cálculo de probabilidades especificadas y la estimación de los valores de la utilidad subjetiva esperada.

Los segundos explican la toma de decisiones atendiendo cómo el individuo representa la situación de decisión, ya que dicha representación mental no es isomorfa respecto a la situación ambiental y sobre esta versará la elección del individuo. En el proceso de representación se contemplan diferentes procesos cognitivos y emocionales, así como sesgos y heurísticos que afectan la toma de decisión, en contraposición a la estructura lógico-deductiva de la aproximación normativa (León, 1987).

Los modelos descriptivos en el campo de la toma de decisiones, así como el realismo y la sociología jurídica en el campo del derecho, resaltan el papel de distintos factores que afectan los supuestos de racionalidad lógica y objetividad de los juicios en la toma de decisiones. En esta línea se enmarca la teoría de racionalidad limitada de Kahneman y Tversky (1979), cuyo supuesto básico es que, en condiciones de juicio y toma de decisiones bajo riesgo e incertidumbre, las personas suelen basarse en juicios intuitivos fundamentados en una serie de conceptos heurísticos simplificadores, sustentados en conocimiento parcial y representaciones que, en algunos casos, pueden resultar sesgadas.

De acuerdo a Kahneman, Slovic, y Tversky (1982), el término heurístico refiere a estrategias cognitivas basadas en una evaluación natural e intuitiva para realizar estimaciones de probabilidades y predicciones con el fin de resolver un problema, reduciendo así su complejidad y requiriendo menor esfuerzo cognitivo. En contraste con una estrategia algorítmica que supone la valoración de todas las posibilidades del espacio-problema, el heurístico se centra en aquellas que en la situación se tornan relevantes, a través de procedimientos de uso habitual como estimaciones de similitud o diferencia, dominancia, representatividad, enmarcamiento, accesibilidad, sobre-confianza, atribución de causalidad, entre otros que pueden llevar a resultados sesgados y sistemáticos, correctos o incorrectos, beneficiosos o no.

Complementando lo anterior, Kahneman (2003) indica que la toma de decisiones individuales puede ser descrita en términos de dos procesos cognitivos denominados Sistema 1 (implícito) y Sistema 2 (explícito): En el Sistema 1 las operaciones mentales vienen determinadas por los hábitos y las costumbres, son impulsivas, automáticas, intuitivas, económicas en términos de los recursos cognitivos, motivadas emocionalmente y son difíciles de controlar o modificar. En este sistema se evidencia una propensión a cometer sesgos y errores sistemáticos en circunstancias específicas de toma de decisiones. Por su parte, el Sistema 2 supone operaciones mentales conscientes, racionales, basadas en creencias, controladas de forma deliberada y vienen determinadas por reglas (eg: algoritmos). Los dos sistemas funcionan simultáneamente de tal forma que el Sistema 2 monitorea los resultados del Sistema 1, y los heurísticos y sesgos resultantes del Sistema 1 pueden afectar los procesos racionales del Sistema 2.

Los sesgos cognitivos se constituyen como una característica del funcionamiento del Sistema 1, en tanto son el resultado de la aplicación intuitiva y no deliberada de un heurístico en el juicio y la toma de decisión. Son definidos como un patrón sistemático de desviación de la norma o racionalidad en el juicio, en el que las inferencias acerca de otras personas y situaciones se derivan de manera ilógica e irracional (Kahneman \& Tversky, 1972; 2000; Haselton, Nettle, \& Andrews, 2005). Particularmente, uno de los dominios sobre los que se ha investigado sistemáticamente la influencia de los sesgos implícitos es el de las actitudes (Nosek B. , 2007). 
Las actitudes se conciben como estimaciones o evaluaciones relativamente duraderas que llevan a cabo las personas sobre lo positivo o negativo que les resultan los objetos o eventos de su entorno. Estas frecuentemente se derivada de creencias, emociones y experiencias pasadas con aquellos objetos o eventos y ejercen una influencia directa sobre el comportamiento presente de las personas (VandenBos, 2007; Vogel \& Wänke, 2016). Dos tipos de actitudes han sido identificadas: las explícitas y las implícitas, cuya diferencia radica básicamente en que las personas pueden describir el origen y justificación de las primeras, mientras que esa información no es accesible o se desconoce en las segundas. Estas últimas son activadas automáticamente por un estímulo (objeto, evento, palabra, etc.) y tienen influencia directa sobre respuestas de forma involuntaria (Nosek \& Banaji, 2009; Wilson, Lindsey, \& schooler, 2000).

La evaluación de actitudes explícitas se ha llevado a cabo predominantemente a través de entrevistas o de instrumentos de autoinforme con escalas tipo Likert o de diferencial semántico. Por su parte, las actitudes implícitas han sido evaluadas a través de instrumentos como el Test de Evaluación Automática (Fazio \& Olson, 2003), la Tarea de Asociación Go/No-Go (Nosek \& Banaji, 2001), y el Test de Asociación Implícita (TAI) (Greenwald, McGhee, \& Schwartz, 1998).

El TAl permite estimar la fuerza asociativa entre conceptosobjetivo (eg: obeso o delgado) y atributos-evaluativos (eg: bueno o malo), midiendo los tiempos de reacción en una tarea computarizada. El supuesto base de este instrumento es que la respuesta conductual resulta más fácil y rápida cuando dos conceptos fuertemente asociados comparten una misma categoría -eg: la latencia al relacionar delgadobueno y obeso-malo puede ser menor que al asociar delgado-malo y obeso-bueno; por tanto, una menor latencia de respuesta representa una mayor fuerza asociativa entre conceptos (Briñol, Horcajo, Becerra, Falces, \& Sierra, 2002)-

Levinson, Cai e Young (2010), realizaron una investigación con 67 jurados elegibles, estudiantes de una universidad estadounidense, con el objetivo de identificar sesgos raciales en la atribución de culpabilidad empleando el TAI. Se presentaron dos atributos-evaluativos (culpable/ no-culpable) y fotos de dos grupos étnicos (blancos/negros). Los participantes debían responder a los pares de estímulos lo más pronto posible, presionando una tecla, Los resultados mostraron que los tiempos de reacción eran más cortos ante emparejamientos culpable/ negro y no-culpable/blanco, poniendo en evidencia una mayor asociación entre estos conceptos y, por ende, un sesgo racial implícito en la atribución de culpabilidad.

Este instrumento ha sido ampliamente utilizado en las últimas décadas para evaluar actitudes implícitas sobre la relación entre los estereotipos de género y la percepción social de la violencia en la pareja (Cantera \& Gamero, 2007); la relación entre tendencias sexuales y personas pedófilas y no-pedófilas (Gray, Brown, MacCulloch, Smith, \& Snowden, 2005); la preferencia entre atributos positivos y personas blancas (Dorantes, Ferrero, \& Tortosa, 2015) y jóvenes (Nosek, Banaji, \& Greenwald, 2002); entre otras. Adicionalmente, sus propiedades psicométricas han demostrado ser robustas (Greenwald, Nosek, \& Banaji, 2003; Nosek, Greenwald, \& Banaji, 2005).

Específicamente en el ámbito de la toma de decisiones judiciales se ha estudiado la influencia de diversos factores relacionados con la cognición implícita, con el objetivo de identificar sesgos y prejuicios. Cahill-O'Callaghan (2013) examinó el papel de los valores personales en la toma de las decisiones judiciales, encontrando que los valores personales están relacionados directamente con los factores de ideología política, activismo, actitudes y demografía, y que influyen de manera significativa e inconsciente la toma de decisiones judiciales, sin intención y sin control por parte del decisor. Por su parte, Collins,
Manning y Carp (2010) buscaron identificar diferencias en la toma de decisiones de jueces hombres y mujeres, cuando había una masa crítica de jueces federales mujeres en la Corte de Distrito de diferentes ciudades de Estados Unidos. Los hallazgos mostraron que las jueces mujeres tomaron decisiones jurídicas de forma distinta a los hombres cuando había una masa crítica con mayoría de jueces mujeres, principalmente en casos penales y en menor medida en casos laborales y de regulación económica.

Con relación al efecto de la edad, el sexo y la raza (de jueces y procesados) sobre las decisiones judiciales, Manning, Carroll y Carp (2004) analizaron 544 resoluciones en casos de discriminación por edad y 1,592 decisiones en casos de discriminación por género y raza. Los resultados revelaron que los jueces más jóvenes eran menos comprensivos con aquellas personas quienes alegaban haber sido víctimas de discriminación por edad, mientras que los jueces más viejos eran más compresivos con ellos. También identificaron un patrón de toma de decisiones más conservativo en casos de discriminación por edad que en casos de discriminación por raza o género.

En el ámbito de los heurísticos, Fariña, Arce y Novo (2002) realizaron un estudio documental (555 sentencias penales pertenecientes a las Audiencias Provincialesy Juzgados Penales de la Comunidad Autónoma Gallega) con el fin de identificar un posible heurístico de anclaje y perfilar los efectos del mismo en la calidad de las decisiones judiciales. Encontraron que el $\mathbf{6 3 . 6 \%}$ del total de las sentencias estaban guiadas por un efecto de anclaje, principalmente derivado de una petición de parte de la fiscalía o de un fallo previo, sesgando así la formación del juicio, la motivación legal y el establecimiento de conexiones causales entre los hechos y el fallo.

En términos de las actitudes implícitas, Rachlinski, Johnson, Wistrich y Guthrie (2009) evaluaron la influencia de asociaciones implícitas sobre las decisiones legales hechas por 133 jueces de primera instancia en Estados Unidos, en tres escenarios hipotéticos en los que la raza del acusado variaba. Utilizaron una tarea de priming subliminal con palabras asociadas a personas afroamericanas y blancas, y dos Test de Asociación Implícita identificando explícitamente la raza del acusado. Los resultados mostraron que los jueces presentaban sesgos implícitos en la atribución de culpabilidad hacia las personas de raza afroamericana en las dos tareas; sin embargo, cuando se hacía explícita la raza y el juez era consciente de ello, el sesgo se reducía.

Finalmente, el juez Anthony Kennedy (miembro de la Corte Suprema de Justicia de Estados Unidos) al referirse a la evidencia empírica recabada durante los últimos 30 años sobre la influencia de los sesgos implícitos sobre la toma de decisiones, reconoció el perjuicio que pueden generar sobre las decisiones legales y llamó la atención sobre las precauciones que deben tener los operadores legales para evitar las desigualdades y discriminaciones derivadas de procesos psicológicos explícitos e implícitos (Science, 2015).

Con base en lo anterior, el objetivo de la presente investigación fue evaluar las actitudes implícitas y explícitas de los defensores de familia (en tanto operadores legales con jurisdicción administrativa) frente a atributos relacionados con las dimensiones de vulnerabilidad - generatividad y conceptos relacionados con factores sociodemográficos de los cuidadores como su oficio, sexo, estatus socioeconómico, orientación sexual y edad. Lo anterior a través de diferentes Test de Asociación Implícita, así como las actitudes explícitas frente a dichos atributos y conceptos. 


\section{Participantes}

Se seleccionó una muestra no probabilística intencional de 26 participantes $\left(M_{\text {edad }}=41.6\right.$ años, rango $=26-58 ; 2$ hombres y 24 mujeres) profesionales en el área del derecho, quienes se desempeñaban como defensores de familia en los Centros Zonales de Huila, Colombia: Neiva (10 participantes), La Gaitana (10), Garzón (1), Pitalito (2), La Plata (2) y Área Técnica (1).

\section{Instrumento Test de Asociación Implícita (TAI)}

Las actitudes implícitas se definen como manifestaciones en forma de acciones o juicios bajo el control de evaluaciones activadas automáticamente sin la mediación de procesos explícitos/conscientes de causación. El TAl permite evaluar estos procesos automáticos, estimando la fuerza asociativa entre estímulos verbales (conceptosobjetivo, atributos-evaluativos y ejemplares) a través de la medición de los tiempos de reacción al responder a arreglos de tales estímulos presentados en una tarea computarizada (Greenwald, McGhee, \& Schwartz, 1998). El supuesto principal es que las asociaciones más fuertemente establecidas entre un concepto-objetivo, un atributo-evaluativo y un ejemplar, son más fáciles de relacionar (menores latencias) que las asociaciones más débiles (mayores latencias).

Para tal fin, este procedimiento permite contrastar las latencias entre una condición en que la relación entre las palabras presentadas es congruente bajo un criterio social y una condición en que tal relación es incongruente. La representación numérica de este contraste se ha denominado Efecto D o Efecto IAT, y se calcula al restarle al promedio de las latencias de la condición congruente, el promedio correspondiente a la condición incongruente. Los valores cercanos a cero indican que no hay diferencias en las latencias entre las dos condiciones, mientras que los valores negativos o positivos indican un sesgo o preferencia en algún sentido.

En los test diseñados para esta investigación se tomaron como atributos-evaluativos las valencias de generatividad y vulnerabilidad identificadas en la Ley 1098 (2006a) en los artículos 51 y 52. Se elaboró una lista con $\mathbf{5 0}$ ejemplares de cada valencia y se solicitó a $\mathbf{1 0}$ operadores legales que seleccionaran los $\mathbf{8}$ más relevantes para cada atributoevaluativo. Posteriormente, los $\mathbf{1 6}$ ejemplares fueron revisados y aprobados por tres (3) jueces expertos, para ser usados en cinco TAl (ver Tabla 2).

Como conceptos-objetivo, se eligieron cinco factores sociodemográficos en dos valencias, que frecuentemente se tienen en cuenta a la hora de valorar la situación de vulnerabilidad o generatividad de un NNA, a saber: oficios (profesionales o no profesionales); sexo (hombre o mujer); estatus-socioeconómico (riqueza o pobreza); orientación sexual (homosexual o heterosexual); y edad (joven o viejo). Cada uno con $\mathbf{8}$ ejemplares seleccionados bajo el mismo procedimiento empleado para los atributos-evaluativos (ver Tabla 2).

Con base en lo anterior se diseñaron cinco (5) TAl (uno para cada factor sociodemográfico) a través del software Authorware 7.0 para ser ejecutados en dos equipos de cómputo (HP-Toshiba) con sistema operativo Windows 7. La interfaz con los usuarios fue el teclado y el programa almacenó automáticamente los datos.

Cada TAl estuvo constituido por cinco (5) fases consecutivas, en consonancia con el procedimiento estándar (Greenwald, Nosek, \& Banaji, 2003; Nosek, Greenwald, \& Banaji, 2007); y para describir dichas fases, se tomará como ejemplo el TAl correspondiente a oficios:

\section{Discriminación de atributos-evaluativos}

Se presentaban 16 ensayos con dos estímulos verbales dicotómicos en los extremos superiores de la pantalla correspondientes a las dos valencias del atributo-evaluativo (eg: vulnerabilidad a la derecha y generatividad a la izquierda), y en la parte media se presentaban de forma aleatoria, ejemplares de cada valencia (eg: vivienda o agresión). La respuesta en esta fase y en las siguientes, consistía en presionar la letra $E$ (izquierda) o la letra I (derecha) del teclado, dependiendo de la relación entre la palabra del medio (ejemplar) y alguna de las palabras de la parte superior (valencia del atributo-evaluativo). Si dicha relación era correcta (eg: vivienda-generatividad-tecla $E$ ), se continuaba con el siguiente ensayo; en caso contrario, aparecía una $X$ roja en el centro de pantalla y se repetía el mismo ensayo hasta que el participante acertara.

\section{Discriminación de conceptos-objetivo}

Tenía la misma estructura de la Fase 1 pero en lugar de atributosevaluativos se presentaban dos valencias de un concepto-objetivo (eg: oficios profesionales a la derecha y oficios no profesionales a la izquierda) y ejemplares de cada atributo (eg: abogado o albañil) en cada ensayo.

\section{Tarea inicial combinada (incompatible)}

Se presentaban 32 ensayos con díadas concepto-atributo en la parte superior de la pantalla (eg: oficios profesionales- vulnerabilidad en la derecha y oficios no profesionales-generatividad en la izquierda) y un ejemplar del concepto o del atributo en la parte media, para cada ensayo (eg: ingeniero o protección). El participante debía categorizar el ejemplar en relación con el concepto o atributo de la díada correspondiente (eg: si aparecía el ejemplar ingeniero, debía presionar la letra I dado que el concepto oficios profesionales se encontraba en la derecha; si aparecía la ejemplar protección, debía presionar la tecla $E$ dado que el atributo generatividad estaba a la izquierda).

En esta fase se consideraba que, por ejemplo, las relaciones oficios no profesionales- generatividad-celador u oficios profesionalesvulnerabilidad-abandono eran incompatibles con la historia de relación entre estos estímulos verbales en las prácticas lingüísticas de la comunidad a la cual pertenecía el participante.

\section{Discriminación de conceptos-objetivo invertida}

Su estructura era similar a la Fase 2, pero se invertía la posición de cada concepto en la pantalla (eg: oficios profesionales a la izquierda y oficios no profesionales a la derecha).

\section{Tarea combinada invertida (compatible)}

Similar a la Fase 3, pero ahora los pares concepto-atributo se invertían (eg: oficios profesionales-generatividad en la derecha y oficios no profesionales-vulnerabilidad en la izquierda). En esta fase se consideraba que, por ejemplo, las relaciones oficios profesionalesgeneratividad-arquitecto $u$ oficios no profesionales-vulnerabilidadmaltrato eran compatibles con la historia de relaciones lingüísticas en las prácticas sociales a las que pertenecía el participante (ver Tabla 2 para la descripción de las fases y los arreglos de estímulos). 
Tabla 2 Conceptos-objetivo, atributos-evaluativos y ejemplares para cada fase de cada TAI

\begin{tabular}{|c|c|c|c|c|c|}
\hline & $\begin{array}{c}\text { Fase 1: } \\
\text { Discriminación } \\
\text { de atributos- } \\
\text { evaluativos } \\
16 \text { ensayos }\end{array}$ & $\begin{array}{c}\text { Fase 2: } \\
\text { Discriminación } \\
\text { de conceptos- } \\
\text { objetivo } \\
16 \text { ensayos }\end{array}$ & $\begin{array}{c}\text { Fase 3: } \\
\text { Tarea combinada } \\
32 \text { ensayos }\end{array}$ & $\begin{array}{l}\text { Fase 4: } \\
\text { Discriminación } \\
\text { de conceptos } \\
\text { reversada } \\
16 \text { ensayos }\end{array}$ & $\begin{array}{l}\text { Fase 5: } \\
\text { Tarea combinada } \\
\text { reversada } \\
32 \text { ensayos }\end{array}$ \\
\hline \multicolumn{6}{|l|}{ TAI - Oficios } \\
\hline \multirow{2}{*}{$\begin{array}{r}\text { Conceptos- } \\
\text { objetivo/ } \\
\text { atributos- } \\
\text { evaluativos }\end{array}$} & \multirow{2}{*}{$\begin{array}{l}\text { *Generatividad/ } \\
\text { Vulnerabilidad* }\end{array}$} & $\begin{array}{l}{ }^{*} \text { Oficios } \\
\text { profesionales }\end{array}$ & $\begin{array}{c}\text { *Oficios } \\
\text { profesionales o } \\
\text { Vulnerabilidad }\end{array}$ & $\begin{array}{l}\text { *Oficios no } \\
\text { profesionales }\end{array}$ & $\begin{array}{c}\text { Oficios } \\
\text { profesionales o } \\
\text { Generatividad* }^{*}\end{array}$ \\
\hline & & $\begin{array}{l}\text { Oficios no } \\
\text { profesionales* }\end{array}$ & $\begin{array}{c}\text { Oficios no } \\
\text { profesionales o } \\
\text { Generatividad }^{\star}\end{array}$ & $\begin{array}{l}\text { Oficios } \\
\text { profesionales* }\end{array}$ & $\begin{array}{l}\text { * Oficios no } \\
\text { profesionales o } \\
\text { Vulnerabilidad }\end{array}$ \\
\hline \multirow{4}{*}{$\begin{array}{r}\text { Estímulos } \\
\text { ejemplares }\end{array}$} & Generatividad: & \multicolumn{4}{|c|}{$\begin{array}{l}\text { Salud, alimentación, vivienda, educación, recreación, apoyo, amory } \\
\text { protección. }\end{array}$} \\
\hline & Vulnerabilidad: & \multicolumn{4}{|c|}{$\begin{array}{l}\text { maltrato, abandono, abuso, encierro, agresión, desnutrición, hacinamiento } \\
\text { y enfermedad. (Estos ejemplares se utilizaron para todos los TAI) }\end{array}$} \\
\hline & Oficios Profesionales: & \multicolumn{4}{|c|}{$\begin{array}{l}\text { abogado, psicólogo, médico, ingeniero, nutricionista, contador, periodista y } \\
\text { arquitecto. }\end{array}$} \\
\hline & Oficios no Profesionales & \multicolumn{4}{|c|}{$\begin{array}{l}\text { albañil, carpintero, empleada doméstica, jardinero, celador, agricultor, } \\
\text { vendedor ambulante, reciclador y mecánico. }\end{array}$} \\
\hline \multicolumn{6}{|l|}{ TAI - Sexo } \\
\hline \multirow{2}{*}{$\begin{array}{l}\text { Conceptos- } \\
\text { objetivo/ } \\
\text { atributos- } \\
\text { evaluativos }\end{array}$} & *Generatividad/ & *Mujer & $\begin{array}{l}\text { *Mujer o } \\
\text { Vulnerabilidad }\end{array}$ & *Hombre & $\begin{array}{l}\text { Hombre o } \\
\text { Vulnerabilidad }\end{array}$ \\
\hline & Vulnerabilidad* & Hombre* $^{*}$ & $\begin{array}{l}\text { Hombre o } \\
\text { Generatividad* }^{*}\end{array}$ & Mujer* $^{*}$ & $\begin{array}{l}\text { *Mujer o } \\
\text { Generatividad }\end{array}$ \\
\hline $\begin{array}{l}\text { Estímulos } \\
\text { ejemplares }\end{array}$ & \multicolumn{5}{|c|}{$\begin{array}{l}\text { Mujer: Mamá, hermana, abuela, tía, madrina, madrastra, vecina, niñera. } \\
\text { Hombre: Papá, hermano, abuelo, tío, padrino, padrastro, vecino, cuidador. }\end{array}$} \\
\hline \multicolumn{6}{|c|}{ TAI - Estatus Socioeconómico } \\
\hline \multirow{2}{*}{$\begin{array}{r}\text { Conceptos- } \\
\text { objetivo/ } \\
\text { atributos- } \\
\text { evaluativos }\end{array}$} & *Generatividad/ & *Riqueza & $\begin{array}{l}\text { *Riqueza o } \\
\text { Vulnerabilidad }\end{array}$ & ${ }^{\star}$ Pobreza & $\begin{array}{l}\text { Pobreza o } \\
\text { Vulnerabilidad* }\end{array}$ \\
\hline & Vulnerabilidad $^{*}$ & Pobreza* & $\begin{array}{c}\text { Pobreza o } \\
\text { Generatividad }\end{array}$ & Riqueza* $^{*}$ & $\begin{array}{l}\text { *Riqueza o } \\
\text { Generatividad }\end{array}$ \\
\hline $\begin{array}{l}\text { Estímulos } \\
\text { ejemplares }\end{array}$ & \multicolumn{5}{|c|}{$\begin{array}{l}\text { Riqueza: Abundancia, exuberancia, placer, dinero, lujos, opulencia, bienes y patrimonio. } \\
\text { Pobreza: Marginalidad, miseria, mendicidad, desamparo, carencia, desempleo, ruina y necesidad. }\end{array}$} \\
\hline \multicolumn{6}{|c|}{ TAI - Orientación Sexual } \\
\hline \multirow{2}{*}{$\begin{array}{r}\text { Conceptos- } \\
\text { objetivo/ } \\
\text { atributos- } \\
\text { evaluativos }\end{array}$} & *Generatividad/ & *Heterosexual & $\begin{array}{l}\text { *Heterosexual o } \\
\text { Vulnerabilidad }\end{array}$ & *Homosexual & $\begin{array}{l}\text { Homosexual o } \\
\text { Vulnerabilidad* }\end{array}$ \\
\hline & Vulnerabilidad ${ }^{*}$ & Homosexual $^{\star}$ & $\begin{array}{l}\text { Homosexual o } \\
\text { Generatividad* }^{*}\end{array}$ & Heterosexual* & $\begin{array}{l}\text { *Heterosexual o } \\
\text { Generatividad }\end{array}$ \\
\hline \multirow{2}{*}{$\begin{array}{r}\text { Estímulos } \\
\text { ejemplares }\end{array}$} & \multicolumn{5}{|c|}{ Heterosexual: Imágenes de parejas heterosexuales } \\
\hline & \multicolumn{5}{|c|}{ Homosexual: Imágenes de parejas homosexuales } \\
\hline \multicolumn{6}{|l|}{ TAI - Edad } \\
\hline \multirow{2}{*}{$\begin{array}{r}\text { Conceptos- } \\
\text { objetivo/ } \\
\text { atributos- } \\
\text { evaluativos }\end{array}$} & *Generatividad/ & *Joven & $\begin{array}{l}\text { *Joven o } \\
\text { Vulnerabilidad }\end{array}$ & *Viejo & $\begin{array}{l}\text { Viejo o } \\
\text { Vulnerabilidad* }\end{array}$ \\
\hline & Vulnerabilidad* & Viejo* $^{*}$ & $\begin{array}{l}\text { Viejo o } \\
\text { Generatividad* }^{*}\end{array}$ & Joven $^{\star}$ & $\begin{array}{l}\text { *Joven o } \\
\text { Generatividad }\end{array}$ \\
\hline $\begin{array}{r}\text { Estímulos } \\
\text { ejemplares }\end{array}$ & \multicolumn{5}{|c|}{ Joven: Imágenes de personas jóvenes } \\
\hline
\end{tabular}

Nota: el asterisco indica la ubicación del estímulo en la pantalla (derecha o izquierda).
Cabe resaltar que en el ejemplo desarrollado se esperaba que las latencias de las respuestas de categorización en la Fase 3 resultaran mayores que las latencias correspondientes a la Fase 5, en tanto se asume que las relaciones compatibles presentan mayor fuerza asociativa entre las palabras que las componen, en contraste con las relaciones incompatibles. Este aspecto constituye el núcleo de la medición de las actitudes implícitas a través del TAI, ya que la diferencia en las latencias entre la fase incompatible (Fase 3) y la fase compatible (Fase 5) permite identificar sesgos implícitos en torno a las asociaciones automáticas entre estímulos verbales que pueden expresarse como acciones o como juicios en la toma de decisiones.

Cabe aclarar que Nosek, Greenwald y Banaji (2007) han reportado evidencia empírica que demuestra que el orden entre las fases 1 y 2 o entre las fases 3 y 5 no afecta los resultados, es decir que evaluar primero la discriminación de conceptos o la de atributos, o evaluar primero las relaciones compatibles o las relaciones incompatibles, no ejerce ningún efecto sobre las medidas recabadas.

\section{Cuestionario de auto- reporte de actitudes explícitas}

Se diseñó un cuestionario dividido en cinco (5) apartados, cada uno correspondiente a los cinco (5) conceptos generales del TAl: oficios, sexo, estatus socioeconómico, orientación sexual y edad. Cada apartado estaba compuesto por 10 preguntas con respuestas cerradas en una escala tipo Likert con 6 valores, que permitió conocer la actitud y preferencia explícita de cada participante en relación con los diferentes tópicos evaluados.

Se tomó como base el aplicativo desarrollado por IAT Corp¹. para adaptar el formato de las preguntas de actitudes explícitas al contexto de la presente investigación y éste fue revisado por tres (3) jueces expertos. Ejemplos del tipo de preguntas para el concepto oficios (profesionales-no profesionales) y el concepto estatus económico (riqueza-pobreza) son los siguientes:

Las personas profesionales brindan mayores factores de generatividad que las personas no profesionales Diferentes ponderaciones se presentan en el grado de riesgo del cuidado de niños, niñas y adolescentes de la gente rica frente a la gente pobre.

Opciones de respuesta:

$\rightarrow$ Totalmente de acuerdo

$\rightarrow$ de acuerdo

$\rightarrow$ ligeramente de acuerdo $\rightarrow$ ligeramente en desacuerdo

$\rightarrow$ en desacuerdo

$\rightarrow$ totalmente en desacuerdo.

\footnotetext{
https://implicit.harvard.edu/implicit/Study?tid=-1
} 
La recolección de datos se llevó a cabo en una sola sesión y de forma individual, en las oficinas de los Centros Zonales del ICBF Huila, en la cual laboraba cada participante. La aplicación de cada TAI se hizo de forma computarizada y el cuestionario sociodemográfico de forma escrita en hojas de papel, en un espacio cerrado, con buena iluminación y sonidos ambientales reducidos.

\section{Procedimiento}

La participación de los operadores legales fue voluntaria y se preservaron los principios establecidos en la normatividad ética y deontológica vigente para la realización de investigaciones empíricas con participantes humanos (Resolución 8430 de 1993; Ley 1090 de 2006, 2006b; APA, 2017).

En primera instancia, se entregó el consentimiento informado a los participantes dando fe que la investigación se realizaba bajo los principios de voluntariedad y confidencialidad. Paso seguido, se entregó el cuestionario de datos sociodemográficos y de actitudes explícitas y se brindó respuesta a todas las dudas e inquietudes.

En segunda instancia, se procedió a dar inicio a cada TAl de forma secuencial (oficios, sexo, estatus económico, orientación sexual y edad, en ese orden). Cada uno iniciaba con la siguiente instrucción en la pantalla:

Instrucción 1: La tarea requiere que usted clasifique palabras o imágenes en categorías, tan rápido como sea posible y cometiendo la menor cantidad de errores. Si realiza el test muy despacio o si comete muchos errores, el resultado no podrá ser interpretado.

Ponga sus dedos índices sobre la letra "E" y en la letra "l" del teclado, para facilitar una respuesta rápida. En la parte superior de la pantalla, aparecerán palabras representando categorías, y en el medio aparecerán palabras representando ítems. Cuando el ítem pertenezca a la categoría de la izquierda, presione la letra "E", cuando el ítem pertenezca a una categoría de la derecha, presione la letra "I".

Los ítems pertenecen a una sola categoría. Si comete algún error, una $X$ aparecerá en la pantalla. Corrija el error respondiendo correctamente.

Para mejores resultados evite las distracciones y permanezca concentrado. Presione el botón "Continuar" para iniciar.

Una vez el participante leía las instrucciones comenzaba la Fase 1 de cada TAI. Posteriormente, antes de iniciar la Fase 3 se presentaba la siguiente instrucción:

Instrucción 2: Observe la parte superior de la pantalla. Las cuatro categorías que vio separadas ahora aparecen juntas. Recuerde que cada ítem pertenece a una única categoría, si comete algún error una $X$ aparecerá en la pantalla. Corrija el error respondiendo correctamente.

Al finalizar la Fase 5 de cada prueba se presentaba la Instrucción 1 correspondientealsiguienteTAI. Unavezsecompletaba laúltima prueba, se agradecía la participación y se almacenaban automáticamente los datos. La sesión individual duraba aproximadamente 45 minutos.

A partir de los datos recabados, se procedió a implementar el algoritmo propuesto por Greenwald, Nosek y Banaji (2003) para calcular el Índice D en cada TAI. Siguiendo dicho algoritmo:

Se eliminaron los ensayos con latencias superiores a $10000 \mathrm{~ms}$
Se eliminaron los datos de cuatro (4) participantes (11, 14, 17 y 23) en tanto presentaron latencias inferiores a $300 \mathrm{~ms}$ en al menos el 10\% de sus respuestas

Se computó la desviación estándar y la media de la ejecución en todos los ensayos de las fases 3 y 5

Se computó la diferencia entre estas medias (MediaFase

3 - MediaFase 5) y se dividió por la desviación estándar compartida

Se obtuvo el Índice D para cada TAl.

\section{Resultados}

En la presente investigación participaron inicialmente 26 defensores de familia adscritos a los Centro Zonales del ICBF-Huila. Este número se redujo a 22 participantes en tanto cuatro de ellos (11, 14, 17 y 23) fueron eliminados, siguiendo el algoritmo propuesto por Greenwald, Nosek y Banaji (2003) para calcular el Índice D en cada TAl.

La Tabla 3 muestra las medias y las desviaciones de las latencias obtenidas en cada fase (medidas en milisegundos), así como los índices del efecto D para cada TAl.

Tabla 3 Medias y desviaciones estándar de las latencias en cada TAl y en cada fase, Índices D y puntuaciones en el cuestionario de actitudes explícitas

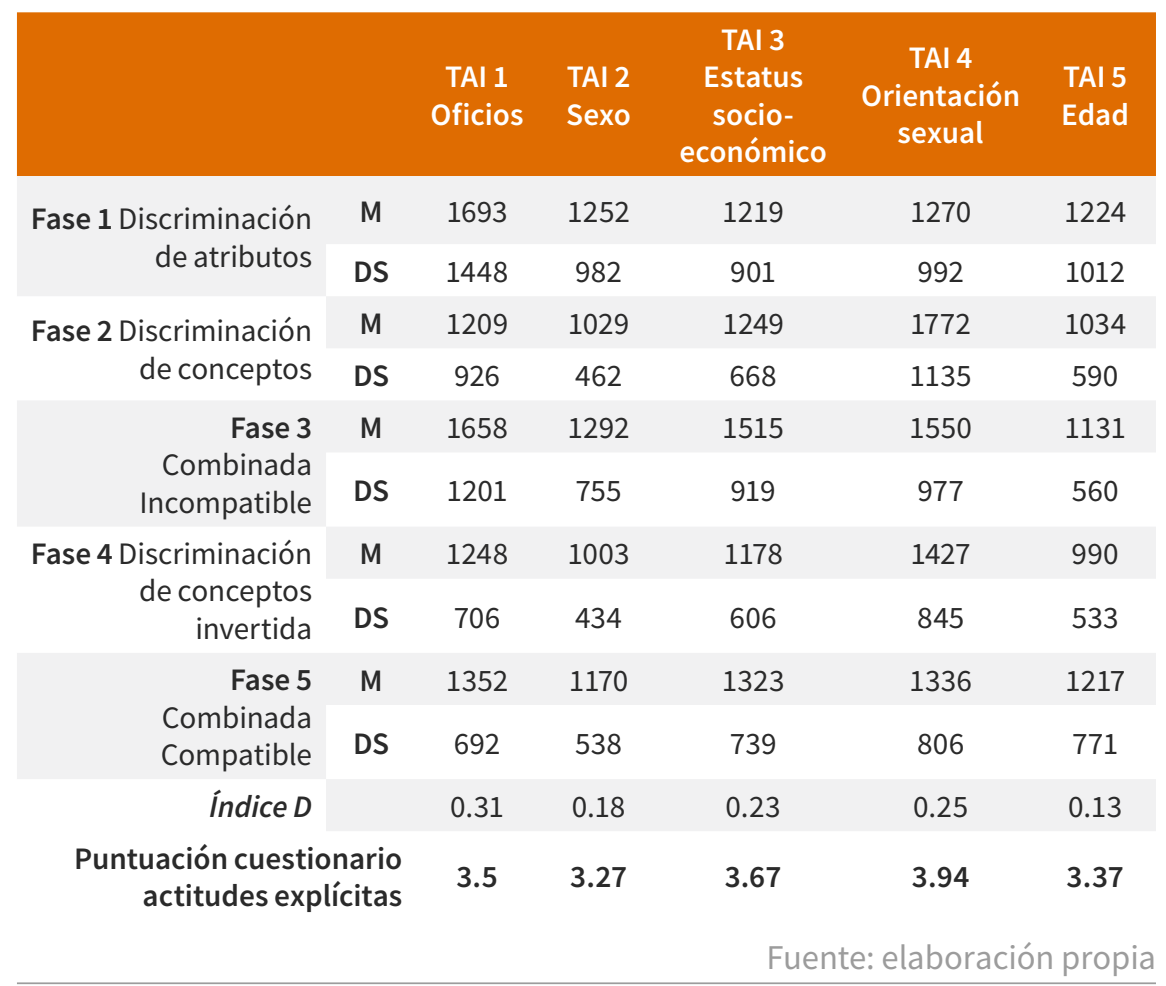

La comparación entre las medianas de las latencias obtenidas en cada fase, entre los diferentes TAl, permitió identificar que en la Fase 1 las latencias entre los distintos TAl fueron significativamente diferentes $\left(X^{2}(4, N=3501)=84.05, p=.00\right)$, siendo significativamente mayores aquellas correspondientes al TAI-oficios en comparación con aquellas de los TAl-sexo ( $Z=-6.31, p=.00)$, TAl-estatus socioeconómico ( $Z$ $=-5.77, p=.00)$, TAl-orientación sexual $(Z=-5.46, p=.00)$ y TAl-edad $(Z=-8.50, p=.00)$. En la Fase 2 también se encontraron diferencias significativas $\left(X^{2}(4, N=3501)=247.82, p=.00\right)$, pero en este caso las latencias en el TAl-orientación sexual fueron superiores a aquellas correspondientes a los otros cuatro TAI (TAI-oficios [ $Z=-10.24, p=.00]$, TAI-sexo [Z = -12.59, $p=.00]$, TAl-estatus socioeconómico [Z = -9.60, p $=.00]$ y TAl-edad [ $=-13.19, p=.00]$ ).

Al realizar esta misma comparación en la fase incompatible (Fase 3) se encontró que las medias de las latencias entre los diferentes TAI difirieron significativamente $\left(X^{2}(4, N=3501)=200.55, p=.00\right)$, siendo menores las medias de las latencias del TAI-sexo en comparación con 
las de los TAl-oficios ( $Z=-7.99, p=.00)$, TAl-estatus socioeconómico ( $Z$ $=-6.44, p=.00)$ y TAl-orientación sexual $(Z=-6.81, p=.00)$. Asimismo, las medias de las latencias del TAl-edad fueron significativamente menores que aquellas correspondientes a los TAl-oficios ( $Z=-11.06$, $p=.00)$, TAl- estatus socioeconómico $(Z=-9.92, p=.00)$ y TAlorientación sexual $(Z=-10.29, p=.00)$. Finalmente, en la Fase 5 (compatible) no se encontraron diferencias significativas entre las latencias correspondientes a los diferentes TAI.

Por su parte, los valores de los Índice D mostraron que en todos los TAl las latencias en la fase incompatible (Fase 3) fueron mayores que en la fase compatible (Fase 5), dado que los valores fueron superiores a 0; sin embargo, los Índice D más altos se encontraron en los TAloficios, TAl-estatus socioeconómico y TAI-orientación sexual. Según Greenwald, McGhee y Schwartz (1998), estos valores (0.31; 0.23 y $\mathbf{0 . 2 5}$, respectivamente) representan un efecto leve-moderado.

Respecto a las ejecuciones en el cuestionario de actitudes explícitas, la Tabla 3 muestra las puntuaciones en un rango entre 1 y 6, dada la estructura de la escala Likert utilizada. Valores cercanos a 1 indican preferencia por una valencia del concepto-objetivo constitutivo de cada TAl (oficios no profesionales, hombre, pobreza, homosexual, viejo, respectivamente) y valores cercanos a 6 indican preferencia por la valencia contraria en cada TAI (oficios profesionales, mujer, riqueza, heterosexual, joven, respectivamente) en relación con los atributos de generatividad y vulnerabilidad en la situación del NNA. Los datos muestran que todas las puntuaciones fueron superiores a 3.0, lo cual indica preferencia por los conceptos relacionados con oficios profesionales, mujer, riqueza, heterosexual y joven como atributos de generatividad; sin embargo, las diferencias entre dichas puntuaciones no fueron estadísticamente significativas.

Al comparar los valores obtenidos a partir del cálculo del Índice D y las puntuaciones conseguidas en el cuestionario de actitudes explícitas, se puede observar una relación directa entre dichos valores: a saber, que los TAl en los que se encontraron los valores más altos de efecto $D$ corresponden con las puntuaciones más altas en los cuestionarios de actitudes explícitas (oficios, estatus socioeconómico y orientación sexual).

\section{Discusión}

El objetivo de este estudio fue evaluar las actitudes implícitas y explícitas de una muestra de defensores de familia adscritos a los Centros Zonales del ICBF-Huila frente a la relación entre las dimensiones de generatividad y vulnerabilidad, y algunos conceptos relacionados con factores socio-demográficos. Igualmente, identificar si se presentaban relaciones entre los dos tipos de actitudes en términos de las puntuaciones obtenidas en los Test de Asociación Implícita y los cuestionarios de auto-reporte.

A partir de los datos recabados tras las ejecuciones en los Test de Asociación Implícita, se llevaron a cabo dos tipos de análisis dentro de cada:

$\rightarrow$ fase para comparar las latencias correspondientes a cada TAI

$\rightarrow$ TAl para comparar las latencias entre las distintas fases.

En el primer caso fue posible identificar que en las comparaciones correspondientes a la Fase 1 las latencias en el TAl-oficios fueron significativamente superiores. Dado que el objetivo de esta fase era únicamente evaluar y entrenar las respuestas de categorización de los ejemplares en relación con los atributos-evaluativos, y que esta fase constituía la primera exposición de los participantes a las pruebas, es posible que la diferencia anteriormente mencionada se debiera a la falta de familiaridad con los arreglos de estímulos y el tipo de respuestas que debía emitirse, promoviendo así tiempos de respuesta más amplios. El hecho que no se presentaran diferencias significativas entre los TAI siguientes apunta en este mismo sentido, en tanto que en los cinco TAl se usaban los mismos estímulos en esta fase.

Por su parte en la Fase 2 las latencias fueron mayores en el TAIorientación sexual, lo cual pudo ser un efecto de que en esta fase los ejemplares eran imágenes de parejas homosexuales o heterosexuales, a diferencia de los anteriores cuyos ejemplares eran palabras. Al respecto puede haber dos explicaciones: una, que el cambio de modalidad verbal a no-verbal en la presentación de los estímulos ejemplares haya auspiciado mayores latencias; dos, que las imágenes no hayan sido suficientemente discriminadas entre sí y, por lo tanto, las respuestas de categorización requirieron más tiempo. Estos dos efectos han sido reportados por Rothermund y Wentura (2004) al diferenciar empíricamente los efectos de las saliencias de los estímulos y las asociaciones entre ellos, cuestiones que pueden ser abordadas empíricamente en futuras investigaciones.

En la Fase 3 (incompatible) las latencias correspondientes al TAl-sexo y al TAl-edad fueron significativamente menores que las correspondientes a los TAl-oficios, estatus socioeconómico y orientación sexual. Esto indica que los tiempos de reacciónal categorizar los ejemplares presentados ante las relaciones incompatibles entre las valencias de sexo o edad y las valencias de vulnerabilidad-generatividad (eg: mujer o joven-vulnerabilidad, hombre o viejo-generatividad) fueron menores que los tiempos de reacción ante las relaciones también incompatibles entre los ejemplares de los conceptos de oficios, estatus socioeconómico y orientación sexual, y los ejemplares de los atributosevaluativos de vulnerabilidad y generatividad (eg: oficios profesionales o riqueza o heterosexual-vulnerabilidad, oficios no profesionales o pobreza o homosexual-generatividad).

Lo anterior contrasta con las ejecuciones en la Fase 5, en la cual las latencias fueron bajas y los participantes tardaron una cantidad equivalente de tiempo en responder a las asociaciones consideradas compatibles entre los ejemplares de los atributos-evaluativos de generatividad y los ejemplares de los conceptos relacionados con oficios profesionales, mujer, riqueza, heterosexual y joven, así como entre los ejemplares de los atributos evaluativos de vulnerabilidad y los ejemplares de los conceptos relacionados con oficios no profesionales, hombre, pobreza, homosexual y viejo.

Con el objetivo de identificar posibles sesgos en las actitudes implícitas respecto a la relación entre factores sociodemográficos y los atributos-evaluativos de generatividad y vulnerabilidad, fue necesario contrastar las latencias correspondientes a la fase compatible y la incompatible a través del cálculo del Índice D. Los datos muestran que estos valores fueron más altos en los TAl de oficios, estatus socioeconómico y orientación sexual, indicando que las latencias en la fase incompatible fueron mayores que las latencias en la fase compatible.

Estos valores representan una fuerza asociativa leve-moderada e indican que los conceptos relacionados con oficios no profesionales, pobreza y homosexualidad resultaron más fáciles de asociar con los ejemplares del concepto de vulnerabilidad (eg: albañil o desamparo o imagen de pareja homosexual-maltrato) que, con los ejemplares relacionados con generatividad, implicando un mayor esfuerzo cognitivo. (Greenwald, McGhee, \& Schwartz, 1998; Greenwald, Nosek, \& Banaji, 2003). Por su parte, para la asociación entre ejemplares de los conceptos de sexo y edad y los ejemplares de vulnerabilidad y generatividad, la diferencia es cercana a 0, por lo cual no es posible identificar claramente un sesgo o estereotipo implícito en estas relaciones. 


\section{Defensores de familia en la toma de decisiones administrativas}

\section{Actitudes implícitas y explícitas}

Lo anterior también indica que los conceptos relacionados con oficios profesionales, riqueza y heterosexualidad, mantienen una fuerza asociativa alta con los atributos evaluativos de generatividad, representando así para este grupo de defensores de familia una garantía de protección y salvaguarda de los derechos de $\mathbf{N N A}$, a saber, ser abogado o ingeniero, lujos u opulencia, heterosexualidad y juventud, resultan ser equivalentes al asociarse con atributos evaluativos de generatividad como protección, amor, salud y educación.

De esta misma forma los conceptos relacionados con oficios no profesionales, pobreza y homosexualidad mantienen una fuerza asociativa alta con los atributos evaluativos de vulnerabilidad, así, albañil o jardinero, desempleo o necesidad y homosexualidad resultan ser equivalentes al relacionarse con atributos negativos que indican vulnerabilidad, como abandono y maltrato.

Estos hallazgos son congruentes con los reportados por CahillO’Callaghan (2013) sobre la influencia de la ideología política, actitudes y demografía de los decisores en la toma de decisiones judiciales. También son congruentes con los reportados por Nosek (2007) sobre el sesgo en la preferencia por la orientación sexual heterosexual y por estatus socio-económico alto, lo cual permite suponer que al momento de tomar decisiones sobre las medidas de restablecimiento de derechos en $\mathbf{N N A}$, los defensores de familia pueden presentar un sesgo o tendencia de forma inconsciente, sin control o intención, estimando la situación de vulnerabilidad o generatividad con base en factores socio-demográficos de pobreza, homosexualidad o de actividades laborales no profesionales de los cuidadores de $\boldsymbol{N N \boldsymbol { A }}$.

Por otra parte, Nosek (2007) plantea que, si en la evaluación de actitudes explícitas e implícitas la relación entre las dos medidas es completamente disímil, es posible que cada instrumento esté evaluando constructos distintos. Sin embargo, cuando se presenta algún nivel de correlación entre las dos medidas es posible que los dos instrumentos estén midiendo el mismo constructo de forma diferente, con la posibilidad que se encuentren preferencias y sesgos.

En la presente investigación, se encontró que las puntuaciones más altas obtenidas en el cuestionario de auto-reporte fueron las correspondientes a oficios, estatus socio-económico y orientación sexual, mostrando una preferencia por la relación entre atributos de generatividad y oficios profesionales, riqueza y heterosexualidad, lo cual se relaciona directamente con los Índice D más altos encontrados en los TAl que abordaban estas mismas características socio-demográficas. Este hallazgo sugiere que, en alguna medida, los defensores de familia son conscientes de su preferencia al relacionar algunos factores sociodemográficos con los atributos de generatividad y vulnerabilidad, lo cual correlaciona con su tendencia implícita en este mismo sentido.

Por otra parte, los Índice D para los conceptos relacionados con edad y sexo fueron leves y se relacionan con puntuaciones bajas en el cuestionario de actitudes explícitas, lo cual puede indicar que no hay preferencias o sesgos en relación con los atributos de generatividad o vulnerabilidad, a pesar que la mayoría de los participantes eran mujeres (92\%). Esto difiere con lo reportado por Collins, Manning y Carp (2010), para quienes el sexo de la masa crítica afecta la toma de decisiones legales a través de un heurístico de representatividad; sin embargo, el efecto reportado por estos autores fue más claro en decisiones de tipo penal y en el caso de los defensores de familia las decisiones son de tipo administrativo, sobre las cuales no hay un cuerpo de evidencia empírica robusta.

Con base en estos hallazgos es posible concluir que los defensores de familia adscritos a los diferentes centros zonales del ICBF-Huila presentan algunos sesgos cognitivos que pueden afectar la toma de decisiones administrativas, lo cual puede llegar a afectar la objetividad en su quehacer profesional. En este sentido, es preciso resaltar que el rol de los defensores de familia, como actores de la función administrativa, se centra en una toma de decisiones que debe velar por la satisfacción de los intereses individuales y/o colectivos, y que genera efectos jurídicos sobre quien recae la decisión. La responsabilidad social que implica esta tarea es evidente y, sin embargo, no ha tenido igual estudio y abordaje como sí lo ha tenido la toma de decisión judicial.

Por un lado, en la defensoría de familia el funcionario tiene un acercamiento diferente con los sujetos que acuden en búsqueda de soluciones a sus conflictos. En este contexto la cercanía entre el funcionario y el usuario marca una diferencia importante en relación con el conocimiento que éste tiene de aquél, lo que conlleva al manejo de información personal de primera mano que termina convirtiéndose en variables que influyen en el proceso de toma de decisiones. Por otro lado, el defensor de familia se permea de unas necesidades individuales, sociales y económicas que de manera paralela deben ser ponderadas con el marco legal de la problemática que le acompaña, buscando de manera creativa soluciones a la situación del usuario; dinámicas que no se encuentran en otros contextos, particularmente el judicial.

Teniendo en cuenta esto, se evidencia la necesidad de integrar los hallazgos de la ciencia psicológica en la formación de las personas encargadas de la toma de decisiones judiciales y administrativas, con el fin de combatir el efecto de los sesgos implícitos, prejuicios y estereotipos sobre la administración de justicia. Esto ya ha sido recientemente propuesto por el Departamento de Justicia de Estados Unidos (Association for Psychological Science, 2016) que pretende vincular este conocimiento a partir del año 2017 en los currículos de formación y entrenamiento de 28,000 empleados, como parte de las políticas de fortalecimiento de la justicia. En palabras del Fiscal General Adjunto Sally Q. Yates:

"Dado que, con base en la investigación, es evidente que la mayoría de las personas experimentan ciertos sesgos inconscientes, y que los efectos de estos sesgos pueden ser contrarrestados mediante el reconocimiento de su existencia y la utilización de estrategias de intervención, es esencial que ofrezcamos formación sobre los sesgos implícitos a todos nuestros fiscales y agentes de la ley" (párr. 5)

\section{Referencias}

APA. (2017). Ethical principles of psychologists and code of conduct. Washington: American Psychological Association. Recuperado de http://www.apa. org/ethics/code/ethics-code-2017.pdf

Association for Psychological Science. (2016, junio 29). Science of Implicit Bias to Be Focus of US Law Enforcement Training. Recuperado de http://www. psychologicalscience.org/index.php/publications/observer/obsonline/ science-of-implicit-bias-to-be-focus-of-us-law-enforcement-training.html

Briñol, P., Horcajo, J., Becerra, A., Falces, C., \& Sierra, B. (2002). Cambio de actitudes implícitas. Psicothema, 14(4), 771-775. Recuperado de http:// www.redalyc.org/html/727/72714413/

Cahill-O'Callaghan, R. J. (2013). The influence of personal values on legal judgments. Journal of Law and Society, 40(4), 596-623. DOI:10.1111/j.14676478.2013.00642.x

Cantera, L., \& Gamero, V. (2007). La violencia en la pareja a la luz de los estereotipos de género. Psico, 38(3), 233-237. Recuperado de https:// dialnet.unirioja.es/servlet/articulo?codigo $=5161622$

Collins, J., Manning, K., \& Carp, R. (2010). Gender, critical mass, and judicial decision making. Law \& Policy, 32(2), 260-281. DOI:10.1111/j.14679930.2010.00317.x 
Colprensa. (2015, septiembre 28). ICBF declara como adoptables a más de 9.500 niños. Recuperado de http://www.eluniversal.com.co/colombia/icbfdeclara-adoptables-mas-de-9500-ninos-207143

Dorantes, G., Ferrero, J., \& Tortosa, F. (2015). Preferencias implícitas de una muestra española: una técnica novedosa para determinar preferencias raciales. Universitas Psychologíca, 14(2), 487-498. DOI:10.11144/Javeriana.upsy14-2.pime

Fariña, F., Arce, R., \& Novo, M. (2002). Heurístico de anclaje en las decisiones judiciales. Psicothema, 14(1), 39-46. Recuperado de http://wwW.redalyc. org/html/727/72714106/

Fazio, R., \& Olson, M. (2003). Implicit measures in social cognition research: Their meaning and use. Annual Review of Psychology, 54, 297-327. DOI:10.1146/annurev.psych.54.101601.145225

Gray, N., Brown, A., MacCulloch, M., Smith, J., \& Snowden, R. (2005). An implicit test of the associations between children and sex in pedophiles. Journal of Abnormal Psychology, 114(2), 304-308. DOI:10.1037/0021-843X.114.2.304

Greenwald, A., McGhee, D., \& Schwartz, J. (1998). Measuring individual differences in implicit cognition: The Implicit Association Test. Journal of Personality and Social Psychology, 74(6), 1464-1480. DOI:10.1037/0022-3514.74.6.1464

Greenwald, A., Nosek, B., \& Banaji, M. (2003). Understanding and using the Implicit Association Test: I. An improved scoring algorithm. Journal of Personality and Social Psychology, 85(2), 197-216. DOI:10.1037/0022-3514.85.2.197

Haselton, M., Nettle, D., \& Andrews, P. (2005). The evolution of cognitive bias. In D. M. Buss, \& D. M. Buss (Ed.), The Handbook of Evolutionary Psychology (pp. 724-746). New Jersey: John Wiley \& Sons Inc.

ICBF. (2008). Lineamientos Técnicos para la Inclusión y Atención de Familias. Bogotá DC [co]: Instituto Colombiano de Bienestar Familiar. Recuperado de http://www.icbf.gov.co/portal/pls/portal/50257.PDF

ICBF. (2017). Lineamiento técnico de modalidades para la atención de niños, niñas y adolescentes, con derechos inobservados, amenazados o vulnerados. Bogotá DC [co]: Instituto Colombiano de Bienestar Familiar. Recuperado de https://www.icbf.gov.co/sites/default/files/procesos/document_19.pdf

Jiménez-Barros, R. (2012). Naturaleza del defensor de familia como institución garante de la eficacia de los derechos de la niñez y la adolescencia. ¿Conciliador o juez? Universitas(124), 169-199. Recuperado de http://wWW. scielo.org.co/scielo.php?script=sci_arttext\&pid=S0041-90602012000100008

Kahneman, D. (2003). A perspective on judgment and choice: mapping bounded rationality. American Psychologist, 58(9), 697-720. DOI: 10.1037/0003-066X.58.9.697

Kahneman, D. (2012). Pensar rápido, pensar despacio. Barcelona: Debate.

Kahneman, D., \& Tversky, A. (1972). Subjective probability: a judgment of representativeness. Cognitive Psychology, 3(3), 430-454. DOI:10.1016/0010-0285(72)90016-3

Kahneman, D., \& Tversky, A. (1979). Prospect Theory: An Analysis of Decision under Risk. Econometrica, 47(2), 263-292.

Kahneman, D., \& Tversky, A. (2000). Choices, Values and Frames. New York: Russell Sage Foundation Cambridge University Press.

Kahneman, D., Slovic, P., \& Tversky, A. (Eds.). (1982). Judgment under uncertainty: Heuristics and biases. New York: Cambridge University Press. DOI:10.1017/CBO9780511809477

León, O. (1987). La toma de decisiones individuales con riesgo desde la psicología. Estudios de psicología, 8(29-30), 79-94. DOI:10.1080/02109395.1987.10821482

Lerner, J., Li, Y., Valdesolo, P., \& Kassam, K. (2015). Emotion and decision making. Annual Review of Psychology, 66, 799-823. DOI:10.1146/annurevpsych-010213-115043

Levinson, J., Cai, H., \& Young, D. (2010). Guilty by implicit racial bias: the guilty/ not guilty implicit association test. Ohio State Journal of Criminal Law, 8, 187-208. Recuperado de https://kb.osu.edu/dspace/bitstream/ handle/1811/73195/OSJCL V8N1 187.pdf
Ley 1090 de 2006, Por la cual se reglamenta el ejercicio de la profesión de Psicología, se dicta el Código Deontológico y Bioético y otras disposiciones (2006b). Recuperado de http://www.secretariasenado.gov. co/senado/basedoc/ley 1090 2006.html

Ley 1098 de 2006, Por la cual se expide el Código de la Infancia y la Adolescencia (2006a). Recuperado de http://www.secretariasenado.gov.co/senado/ basedoc/ley 1098 2006.html

Manning, K., Carroll, B., \& Carp, R. (2004). Does Age Matter? Judicial decision making in age discrimination cases. Social Science Quarterly, 85(1), 1-18. Recuperado de https://www.umassd.edu/media/umassdartmouth/ politicalscience/facultydocs/klmssq04.pdf

Nosek, B. (2007). Implicit-explicit relations. Current Directions in Psychological Science, 16(2), 65-69. DOI:10.1111/j.1467-8721.2007.00477.x

Nosek, B., \& Banaji, M. (2001). The go/no-go association task. Social Cognition, 19(6), 625-666. DOI:10.1521/soco.19.6.625.20886

Nosek, B., \& Banaji, M. (2009). Implicit attitude. In T. B. P. Wilken (Ed.), Oxford Companion to Consciousness (pp. 84-85). Oxford, UK: Oxford University Press.

Nosek, B., Banaji, M., \& Greenwald, A. (2002). Harvesting implicit group attitudes and beliefs from a demonstration web site. Group Dynamics: Theory, Research and Practice, 6(1), 101-115. DOI:10.1037/1089-2699.6.1.101

Nosek, B., Greenwald, A., \& Banaji, M. (2005). Understanding and using the Implicit Association Test: II. Method variables and construct validity. Personality and Social Psychology Bulletin, 31(2), 166-180. DOI: $10.1177 / 0146167204271418$

Nosek, B., Greenwald, A., \& Banaji, M. (2007). The Implicit Association Test at age 7: A methodological and conceptual review. In J. Bargh (Ed.), Social Psychology and the Unconscious: The Automaticity of Higher Mental Processes (pp. 265-292). New York: Psychology Press. Recuperado de https://faculty.washington.edu/agg/pdf/Nosek\%20\&\%20al.IATatage7.2007.pdf

OIM/WMO. (2013). Mapas de vulnerabilidad, riesgos y oportunidades (MVRO). Bogotá DC [co]: Organización Internacional para las Migraciones. Recuperado de https://rni.unidadvictimas.gov.co/sites/default/files/ Documentos/

Over, D. (2004). Rationality and the normative/descriptive distinction. In D. Koehler, \& N. Harvey., Blackwell Handbook of Judgment and Decision Making (pp. 3-18). London: Blackwell Publishing Ltd. Recuperado de https://pdfs. semanticscholar.org/e8e6/a44919fe51cf94ddccd670a389be59acbb5a.pdf

Rachlinski, J., Johnson, S., Wistrich, A., \& Guthrie, C. (2009). Does Unconscious Racial Bias Affect Trial Judges? Cornell Law Faculty Publications., 84(3), 1195-1246. Recuperado de https://scholarship.law.cornell.edu/cgi/ viewcontent.cgi? article $=1691 \&$ context $=$ facpub

Resolución 8430 de 1993, Por la cual se establecen las normas científicas, técnicas y administrativas para la investigación en salud (1993). Recuperado de https://www.minsalud.gov.co/sites/rid/Lists/BibliotecaDigital/RIDE/DE/DIJ/ RESOLUCION-8430-DE-1993.PDF

Rothermund, K., \& Wentura, D. (2004). Underlying Processes in the Implicit Association Test: Dissociating Salience from Associations. Journal of Experimental Psychology: General, 133(2), 139-165. DOI:10.1037/0096-3445.133.2.139

Science, A. f. (2015, julio 5). US Supreme Court Recognizes Role of Unconscious Bias in Disparate Treatment. Recuperado de http://www. psychologicalscience.org/index.php/news/releases/us-supreme-courtrecognizes-role-of-unconscious-bias-in-disparate-treatment.html

VandenBos, G. R. (Ed.). (2007). APA dictionary of psychology. Washington, DC: American Psychological Association. Recuperado de http://psycnet.apa. org/record/2006-11044-000

Vogel, T., \& Wänke, M. (2016). Attitudes and attitude change. NY: Taylor \& Francis Recuperado de http://www.worldcat.org/title/attitudes-and-attitudechange/oclc/875096862

Wilson, T., Lindsey, S., \& Schooler, T. (2000). A model of dual attitudes. Psychological Review, 107(1), 101-126. DOI:10.1037/0033-295X.107.1.101

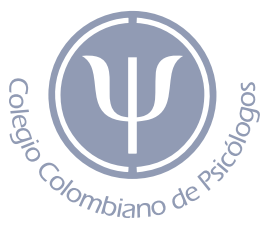

